\title{
RETENTION SOIL FILTER FOR TREATMENT OF COMBINED SEWER OVERFLOW AND WASTEWATER TREATMENT PLANT EFFLUENT
}

\author{
KATHARINA KNORZ, FRANZ-MICHAEL MERTENS, ANDREA F. BRUNSCH \\ \& EKKEHARD CHRISTOFFELS \\ Erftverband, Bergheim, Germany
}

\begin{abstract}
Point sources such as wastewater treatment plants (WWTP), combined sewer overflows (CSO) and separate sewer outlets (SSO) are acknowledged to be major pathways for pollutants to enter surface water. As response, retention soil filters (RSF) have been installed among others in the Erft river catchment area over the past two decades to treat outflows of combined sewer systems and rainwater from separate sewer systems. Studies conducted on several of these RSFs have shown that besides reducing solids by filtration, RSFs have good chemical and biological cleaning capacities for a variety of parameters. Concentrations of both nutrients and heavy metals are reduced. Numerous micropollutants such as pharmaceuticals, pesticides and industrial compounds as well as faecal bacteria are eliminated at high rates. With this background a new type of RSF (RSFplus) has been designed for the flexible treatment of WWTP effluent and CSO. The RSF plus treats CSO during rain events. During dry weather periods, the RSF ${ }^{\text {plus }}$ is used for polishing WWTP effluent. The RSF ${ }^{\text {plus }}$ is divided into three segments which are fed alternately to guarantee aerobic conditions and is equipped with innovative distribution channels to ensure homogeneous feeding. Granulated activated carbon is used as an additive for the filter medium for advanced treatment. The effectiveness of WWTP effluent polishing and reliability of operational parameters have already been tested for 2.5 years on a pilot scale. The first full-scale demonstration site will be built in 2017 at the WWTP Rheinbach in North Rhine-Westphalia (Germany).
\end{abstract}

Keywords: combined sewer overflow, micropollutants, nutrients, retention soil filter, wastewater treatment plant

\section{INTRODUCTION}

With the adoption by the European Union of the Water Framework Directive in 2000, regulations were established on surface water quality [1]. Water courses that are mostly fed by combined sewer overflows (CSOs) and separate sewer outlets (SSOs) are of special concern. To reduce pollutant loads during event-specific inflows, especially in North Rhine-Westphalia retention soil filters (RSFs) have been installed below stormwater basins for the treatment of rainwater and CSOs. Besides performing mechanical and biological treatment, RSFs are recognized for reducing hydraulic stress on receiving water bodies [2]. The addition of a list of priority substances to the Water Framework Directive has helped to bring chemical water quality into focus. Studies have shown that conventional WWTPs are not able to reduce micropollutants, which has led to an increased demand for additional treatment steps.

RSFs have already proven their effectiveness in treating CSOs and SSOs. Results from studies of filter material and water samples in the Erft catchment area will be presented in this article. According to Scheurer et al. [3], chemical cleaning capacities of RSFs for certain substances are comparable to those of activated sludge treatment. Moreover, nutrient retention rates of more than $75 \%$ have been reported [4]. Good elimination rates for heavy metals, numerous micropollutants such as pharmaceuticals, pesticides and industrial wastes as well as faecal bacteria have been shown $[2,3,5]$. 


\section{CONVENTIONAL RETENTION SOIL FILTERS}

Since 1997, 32 RSFs have been installed by the Erftverband water management association in the Erft catchment area. All of these RSFs are still in use.

The majority of the Erftverband RSFs were built between 2000 and 2005 and are used for the treatment of CSOs. Only 5 of the 32 RSFs are fed by SSOs. A schematic view of the structure of RSFs is shown in Fig. 1.

RSFs consist of sand as filter material to which 20-30 vol.- $\%$ of $\mathrm{CaCO}_{3}$ is added. A drainage layer consisting of gravel and drainage pipes to channel the treated water to the receiving river is installed below the filter body. Beneath the drainage layer the RSF is sealed by a sealing membrane to protect the soil layers below the filter body and the groundwater from contamination. RSFs are planted with reeds to avoid clogging. Only five RSFs have either lawn or yarrow vegetation.

RSFs in the Erft catchment area vary in size with filter areas spanning from $80 \mathrm{~m}^{2}$ to more than $5,000 \mathrm{~m}^{2}$ depending on the connected urban drainage area they serve. Dimensions are determined by the RSF guideline of North Rhine-Westphalia DWA-M-178 [6]. RSFs differ in their distribution of CSO over the filter surface. This difference has major impact on the loading of the filter material. While some RSFs have only one overspill at the inflow (Fig. 2A), there are others with distribution channels across the filter area to guarantee homogeneous feeding (Fig. 2B).

\subsection{Sampling strategy}

To comply with relevant permits soil samples have to be taken every 5 years to measure the contamination of the filter material. To measure the purification efficiency, water samples have been analysed in the course of studies funded by the state government for promotion of research and innovation projects [8].

Filter material samples from 24 RSFs constructed between 1999 and 2011 were taken to examine the degree of contamination and to estimate their remaining lifetime. The remaining eight RSFs were too new for filter material analysis. Sampling took place close to and at a

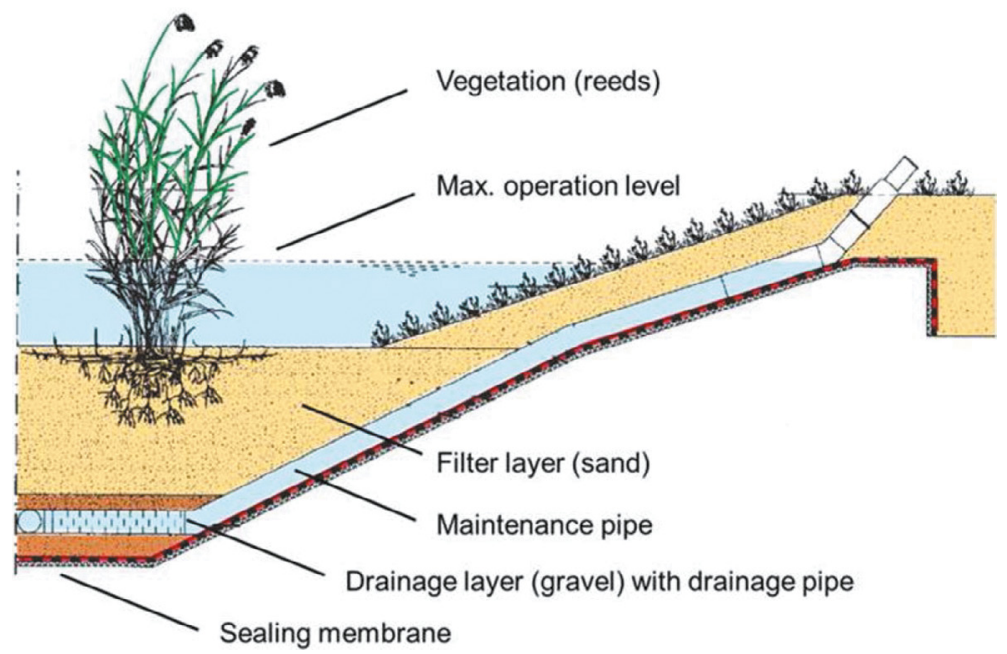

Figure 1: Structure of a conventional RSF [7]. 


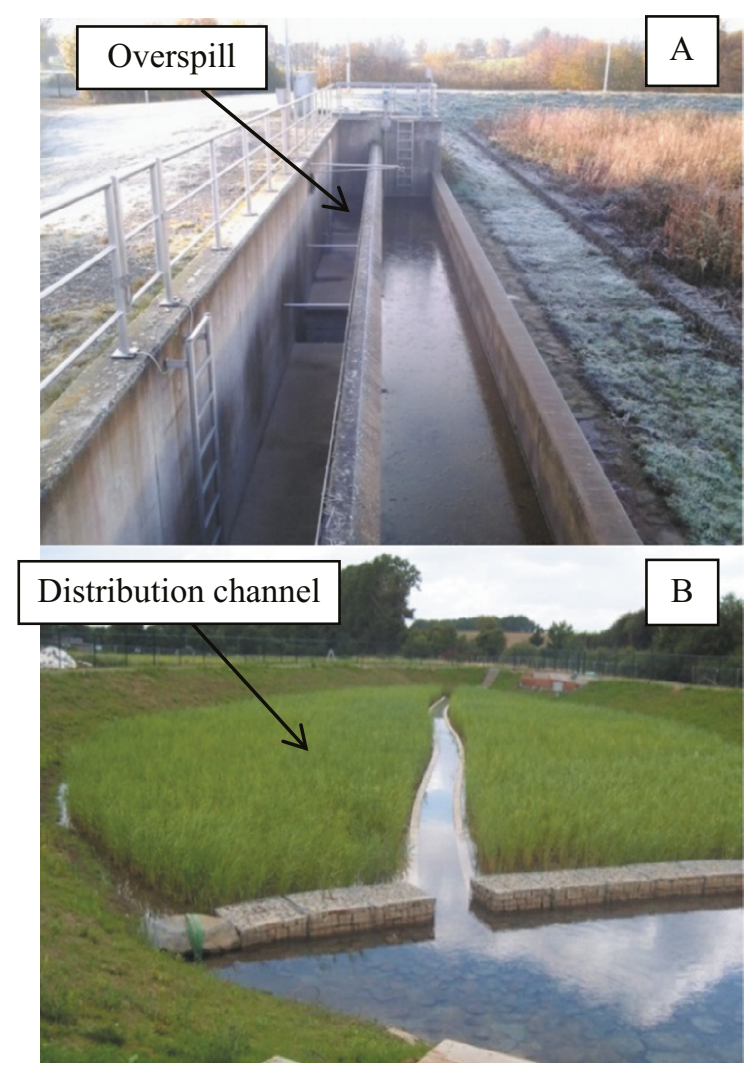

Figure 2: Distribution systems of RSFs.

greater distance from the inflow. The filter material was sampled from different depths $(0-5$, 5-10, 10-30, 30-60 cm), with six samples taken at each depth. Composite samples were then obtained from each depth. For samples of the upper two layers a spade was used whereas for depths greater than $10 \mathrm{~cm}$ an Edelman auger for sandy soil was employed. Besides nutrients and heavy metals, organic matter, carbonate concentrations and micropollutants were analysed.

Water samples were taken at the inflow and outflow of two representative RSFs, in Altendorf and Kaster (North Rhine-Westphalia). Both have been in use since 2005. For this purpose, autosamplers were installed at the inflow and outflow to collect 12-min composite samples of $2.9 \mathrm{~L}$ over a maximum of $132 \mathrm{~min}$ at RSF Altendorf. At RSF Kaster, the maximum sampling time at the outflow was raised to $150 \mathrm{~min}$. At the inflow, three composite samples were taken in the periods of 0-15 $\mathrm{min}, 15-60 \mathrm{~min}$ and 60-90 min. Physico-chemical as well as microbiological analysis was performed according to Christoffels et al. [2].

\subsubsection{Results}

Depending on the age of RSFs and the frequency of feeding, organic matter accumulated mostly in the upper layer. Pollutants clearly accumulated within this upper humous layer as shown in Fig. 3 with the example of zinc. The amount of organic matter as well as the amount of pollutant load within the filter medium decreased with depth. 

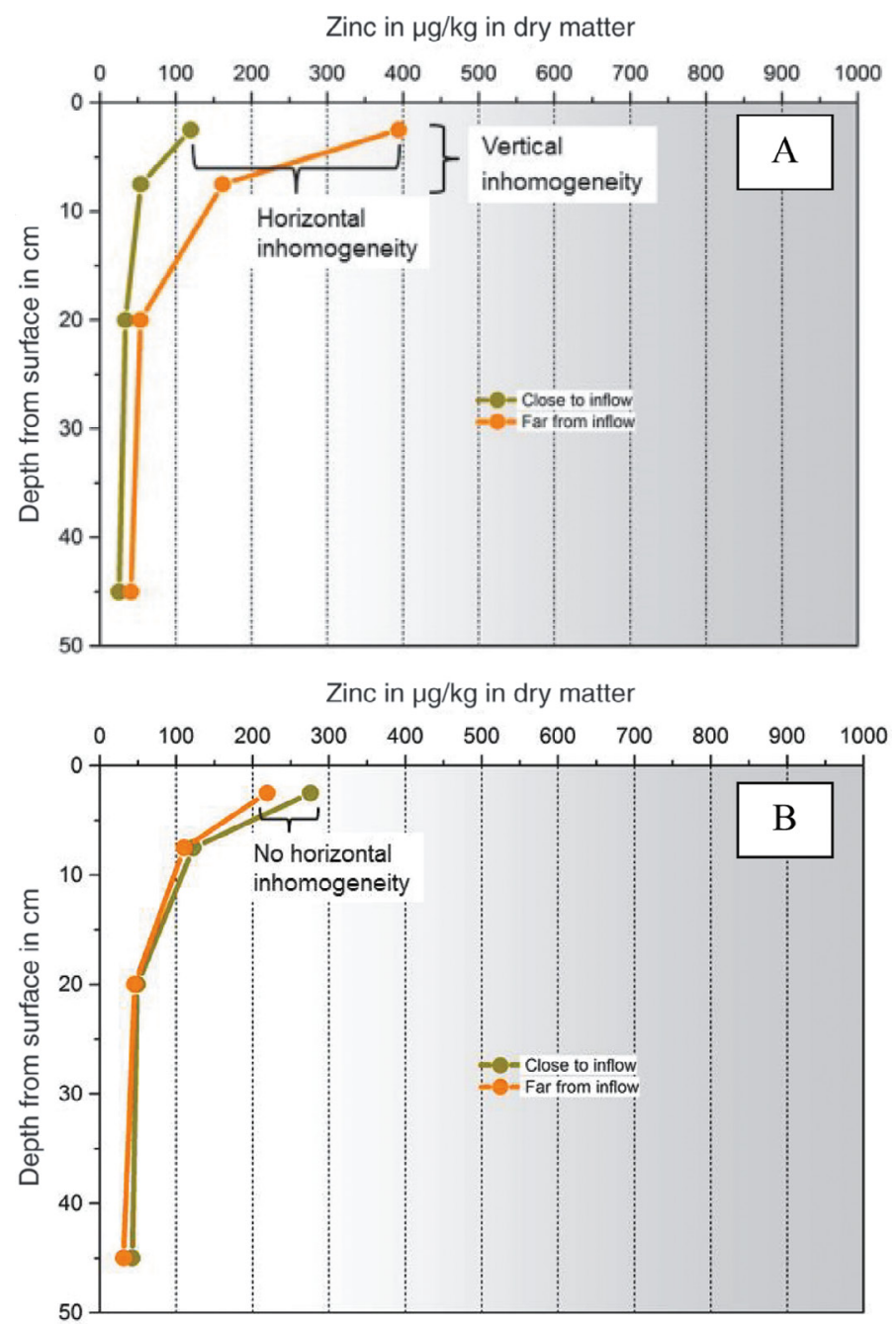

Figure 3: Substrate analysis of zinc picturing vertical and horizontal inhomogeneities of the filter medium.

Besides the vertical inhomogeneity of pollutant concentration, an unequal distribution of the horizontal burden can be seen (Fig. 3A). The filter sand close to the inflow is more contaminated than the material further away from the inflow. This effect is clearly seen for RSFs with only one overspill (compare Fig. 2A). RSFs with distribution channels (compare Fig. 2B) showed less difference in their horizontal pollution profiles (Fig. 3B). In this case, the filter medium is evenly loaded.

$\mathrm{CaCO}_{3}$ concentrations were found to be a suitable factor for evaluating the total burden on the RSF. Carbonate stabilizes the $\mathrm{pH}$ during nitrification processes. A depletion in $\mathrm{CaCO}_{3}$ leads to acidification of the soil and hence the remobilization of heavy metals. The $\mathrm{pH}$ value was stable in all filter material samples, though a reduction in $\mathrm{CaCO}_{3}$ was noticeable. 
Critical depletion of $\mathrm{CaCO}_{3}$ was detected in some RSFs with a reduction of $\mathrm{CaCO}_{3}$ concentrations down to $2.5 \%$ in the upper layer. This corresponds with the relatively high concentrations of organic matter and pollutants in this layer. RSFs with higher pollution loads due to more frequent CSO events or larger amounts of water during CSOs are more likely to deplete in $\mathrm{CaCO}_{3}$ than RSFs with low pollution loads. So far, a remobilization of pollutants has not occurred in any of the 24 studied RSFs, which leads to the conclusion that cleaning performance is guaranteed for an operational life of at least 10 years.

Water samples show complementary results. In total, 35 CSO events were analysed with 354 samples from both the inflow and outflow at RSF Altendorf. At RSF Kaster, 23 CSO events with 69 samples from both the inflow and outflow were assessed.

Filtration reduced suspended solids by median concentrations of $98 \%$ at RSF Altendorf and $91 \%$ at RSF Kaster. Along with the reduction of solid material, pollutants sorbed to the solid material were reduced. Nitrogen compounds such as ammonia were restrained by $98 \%$ in median value at RSF Altendorf and by $94 \%$ at RSF Kaster. Concentrations of heavy metals were also reduced. For example, median retention rates for zinc were $82 \%$ and $71 \%$ at RSF Altendorf and RSF Kaster, respectively. Similar results have been reported by Frechen [4]. Retention rates of more than $55 \%$ and of greater than $20 \%$ as a median are achieved for phosphorus and orthophosphate-phosphorus, respectively (Fig. 4). These divergent results suggest that especially dissolved phosphorus is not retained very well. Total organic carbon (TOC) concentrations are reduced by more than $70 \%$ at RBF Altendorf and $50 \%$ at RBF Kaster as a median.

High reduction rates for some micropollutants were detected. In contrast to the abovementioned substances, micropollutants showed a higher variance in retention rates based on their substance-specific characteristics. Diclofenac and Ibuprofen were reduced by more than $65 \%$ (Fig. 5). Median reduction rates of more than $90 \%$ for caffeine and Metformin were

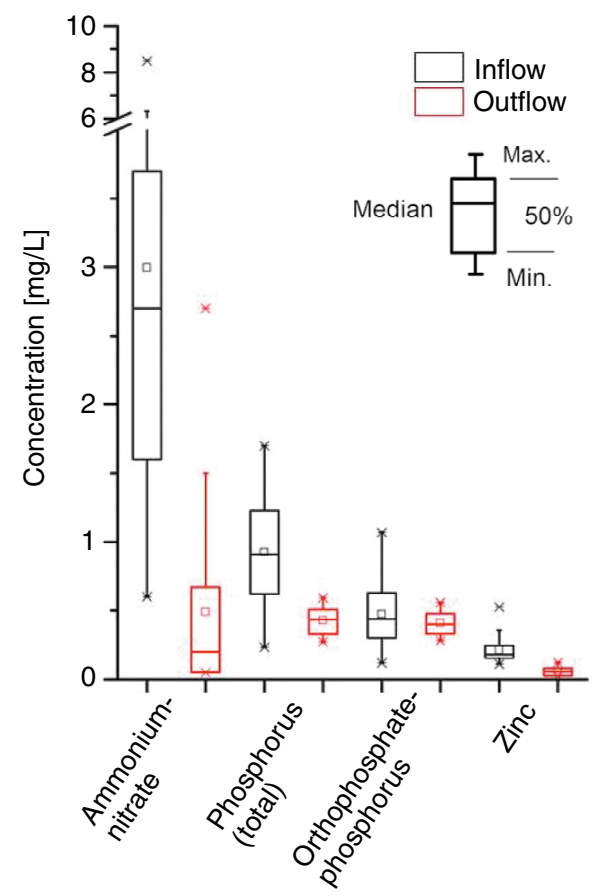

Figure 4: Results of chemical-physical analysis of water samples of RSF Kaster. 


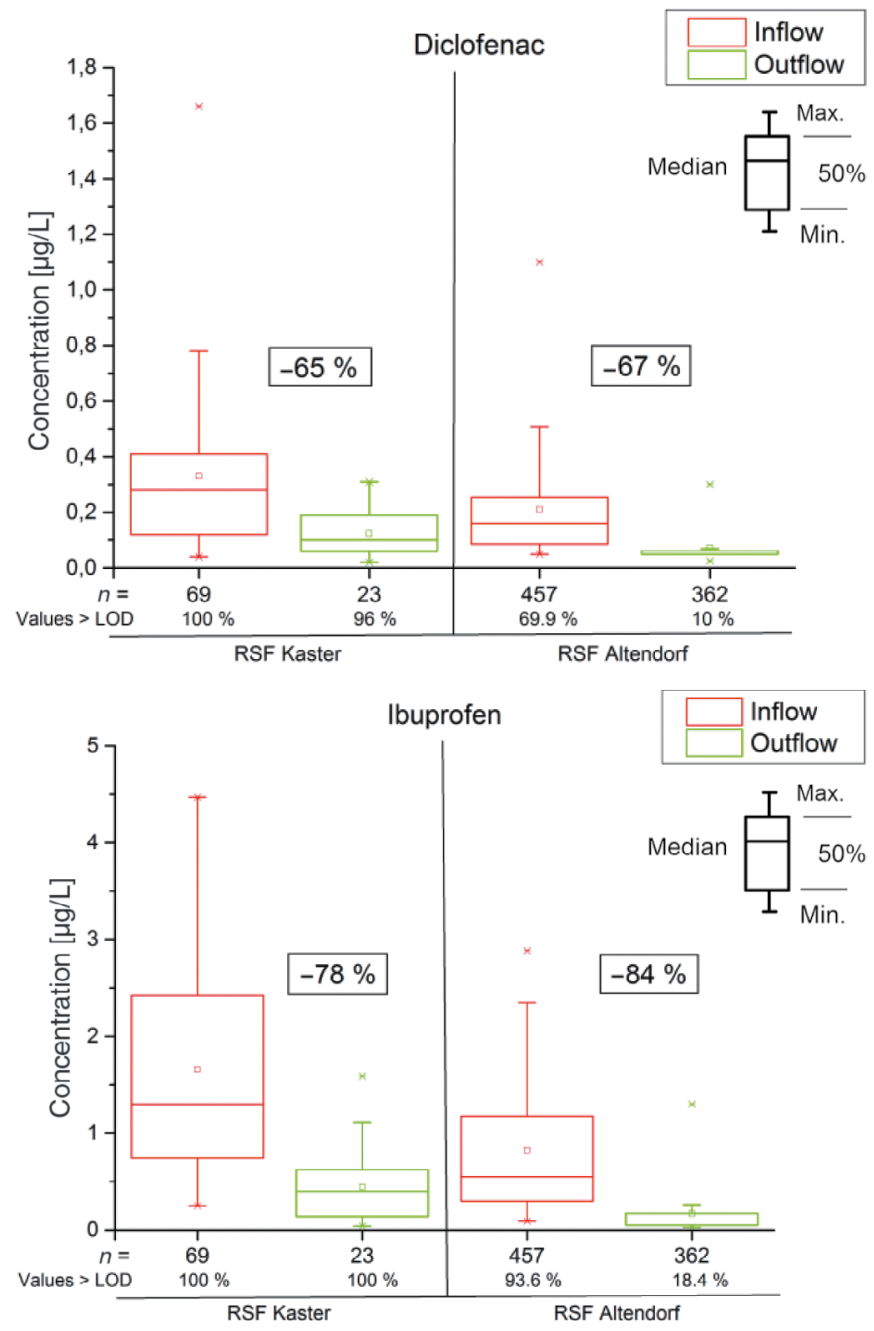

Figure 5: Concentrations of Diclofenac and Ibuprofen at inflow and outflow of RSF Kaster and RSF Altendorf (LOD = limit of detection), respectively.

detected. Metoprolol and Bisphenol-A were reduced by more than $80 \%$ as a median. Tondera et al. [5] and Scheurer et al. [3] have obtained similar results.

\subsubsection{Assessment of results}

The results obtained from the water samples show that RSFs can provide very good chemical cleaning performance with regard to physico-chemical parameters and that good retention rates for micropollutants can also be achieved. In this study, the cleaning capacity of RSFs was only measured for CSOs and SSOs. However, Scheurer et al. [3] report that removal capacities of RSFs are comparable to those achieved by activated sludge treatment.

Results obtained from the filter material sampling indicate long operational lifetimes of RSFs without further investment costs. So far, no breakthrough of pollutants has been 
detected. However, differences in the degree of contamination of RSFs can be seen, depending on their constructional and operational parameters. RSFs characterized by a point load due to only one overspill show higher contamination close to the inflow than away from the inflow. The study showed that distribution channels have the ability to distribute wastewater evenly, which assures homogeneous loading of the filter medium.

Organic matter accumulated in the upper layer of the filter medium. That way sorption processes of pollutants by the humous layer are improved. A high frequency of overflow events as well as high loads of wastewater during these events led to the largest decrease in $\mathrm{CaCO}_{3}$ concentrations in the upper layer of the filter medium. Nonetheless, both water and filter material samples clearly showed that even after an operational lifetime of 10 years cleaning performance is maintained.

Besides good chemical cleaning capacities and long lifetimes the studied RSFs only needed small amount of maintenance during their entire operational lives. In this respect, they offer an effective tool for low-cost and reliable water purification.

Given the fact that overflow events occur only a few times a year, RSFs could be used for further cleaning purposes during dry weather periods. The idea of advanced treatment of WWTP effluent by RSFs to reduce the micropollutant burden of receiving watercourses during periods with no overflow events is worthy of consideration.

\section{PERSPECTIVE: RSF ${ }^{\text {PLUS }}$}

Based on the above-mentioned results, the effectiveness of RSFs with substrate additives for WWTP effluent purification will be investigated. A new kind of RSF (RSFlus) for the flexible treatment of CSO and wastewater treatment plant (WWTP) effluent has been designed. The RSF ${ }^{\text {plus }}$ is constructed on the site of a WWTP with CSO basin. An additional flocculation filtration stage is mandatory. As shown in Fig. 6, the RSF plus is fed by WWTP effluent during dry weather to serve as a fourth treatment step. During storm events, the CSO is discharged onto the RSF ${ }^{\text {plus }}$. At these times, the WWTP effluent is discharged directly into the receiving river.

\subsection{Framework of preliminary studies}

The effectiveness of RSFs in performing WWTP effluent polishing was tested at pilot scale. The pilot plant is located at the WWTP in Rheinbach, North Rhine-Westphalia. WWTP

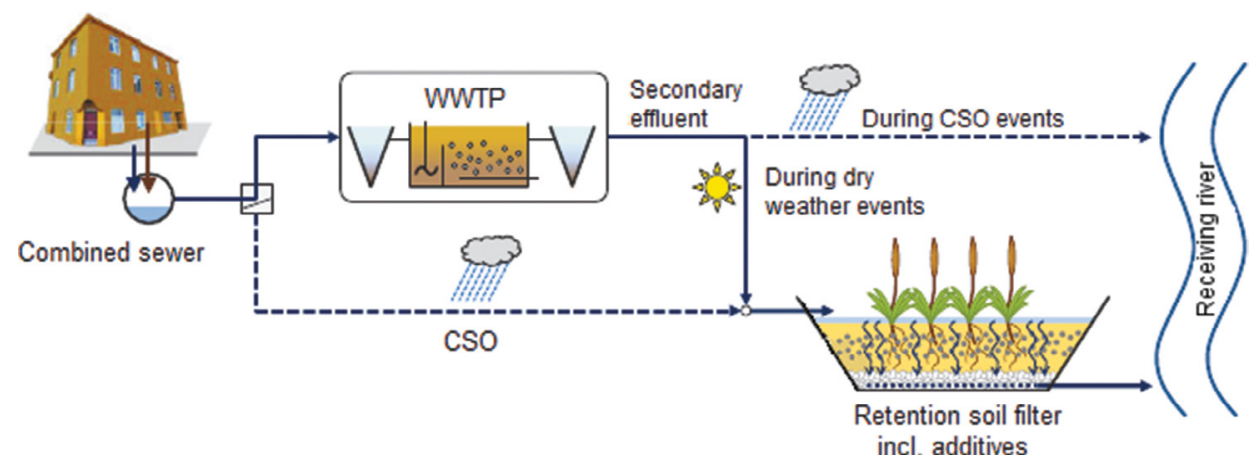

Figure 6: Schematic view of RSF ${ }^{\text {plus }}$ system for flexible treatment of CSO and WWTP effluent [9]. 
Rheinbach is designed for a population equivalent of 27,000 and is equipped with an additional flocculation filtration. Three individual pilot-scale RSFs, each with a volume of $1.39 \mathrm{~m}^{3}$, were examined over a period of 2.5 years. The pilot system delivered information about the stability of operational parameters, the use of different substrate additives and the lifetime of RSFs utilized for WWTP effluent polishing.

In contrast to conventional RSFs the pilot system is fed periodically with WWTP effluent. The study showed that for a feeding period over $28 \mathrm{~h}$ and a dry period of $56 \mathrm{~h}$ aerobic conditions are suitable. The corresponding feeding rate was set to $0.03 \mathrm{~L} / \mathrm{s} / \mathrm{m}^{2}$ according to the RSF guideline from North Rhine-Westphalia DWA-M-178 [8]. Oxygen conditions remained adequate and the $\mathrm{pH}$ remained stable during the study. Hence, periodic feeding of the RSF did not lead to remobilization of heavy metals.

While two of the three pilot-scale RSFs consist of conventional filter material, granular activated carbon (GAC) was added to the filter material of the third pilot-scale RSF to test the influences of GAC on clogging. The studies showed no influence on operational parameters. Clogging did not occur during the investigation.

\subsubsection{Demonstration site}

A first full-scale demonstration site to deploy RSF plus for flexible treatment of CSO and WWTP effluent will be built in 2017 at the WWTP in Rheinbach. The RSF is designed to treat the CSO during heavy rain events, according to the RSF guideline from North RhineWestphalia DWA-M-178 [8]. In this application, the filter medium will cover an area of $5,000 \mathrm{~m}^{2}$.

During dry weather periods, the average daily inflow amounts to $50 \mathrm{~L} / \mathrm{s}$ for the demonstration site. At night, it reduces to approximately $17 \mathrm{~L} / \mathrm{s}$. CSO events with an inflow of up to 3,000 L/s are possible.

To guarantee aerobic conditions in the filter medium, the RSF ${ }^{\text {plus }}$ is separated into three equally sized segments that are fed alternately (Fig. 7). A cycle of $24 \mathrm{~h}$ of feeding and $48 \mathrm{~h}$ of dry phase appears to be appropriate according to preliminary studies. After feeding of one segment for $24 \mathrm{~h}$, the segment is emptied within a few hours. The remaining time until feeding serves as aeration phase to guarantee aerobic filter conditions.

Distribution channels are necessary for homogeneous loading of RSFplus. Two distribution channels are arranged radially in each segment. At an interval of $4 \mathrm{~m}$, circular flaps are installed on the distribution channels. Depending on the amount of water the distribution channels fill evenly to a certain level. The flaps act as throttle and release nearly the same amount of water close to and far from the inflow onto the filter body. This way the small amount of feeding water during dry periods can be homogeneously distributed over the entire filter area.

As with conventional RSFs, sand is used as filter material. About $20-30$ vol.- $\%$ of $\mathrm{CaCO}_{3}$ is added to the filter sand. In contrast to conventional RSFs, however, GAC is added to improve micropollutant reduction, and 10 vol.- $\%$ is added to the upper $10 \mathrm{~cm}$ of the filter. For the purpose of study, different amounts of GAC are added to the lowest $30 \mathrm{~cm}$ of the filter. Segments 2 and 3 of the RSF plus contain 30 and 40 vol.-\% GAC, respectively. Segment 1 does not contain any GAC in the lowest layer and serves as a reference medium. The structure of the RSF ${ }^{\text {plus }}$ is shown in Fig. 8.

\subsubsection{Monitoring}

A sophisticated monitoring system is to be installed at the RSF plus to observe cleaning performance. Besides autosamplers at the inflow and outflow of the RSF ${ }^{\text {lus }}$, sampling points are 


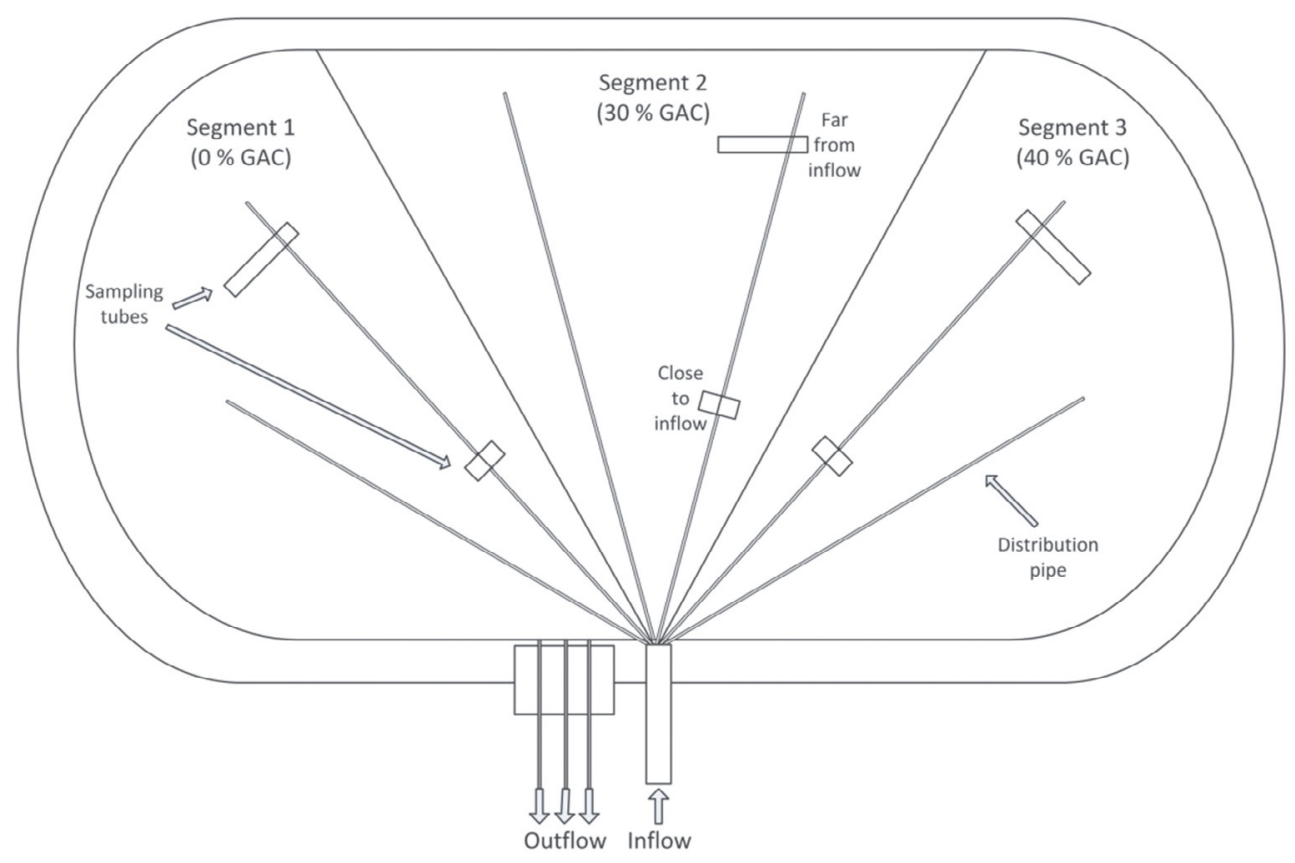

Figure 7: Plan of the RSFplus.

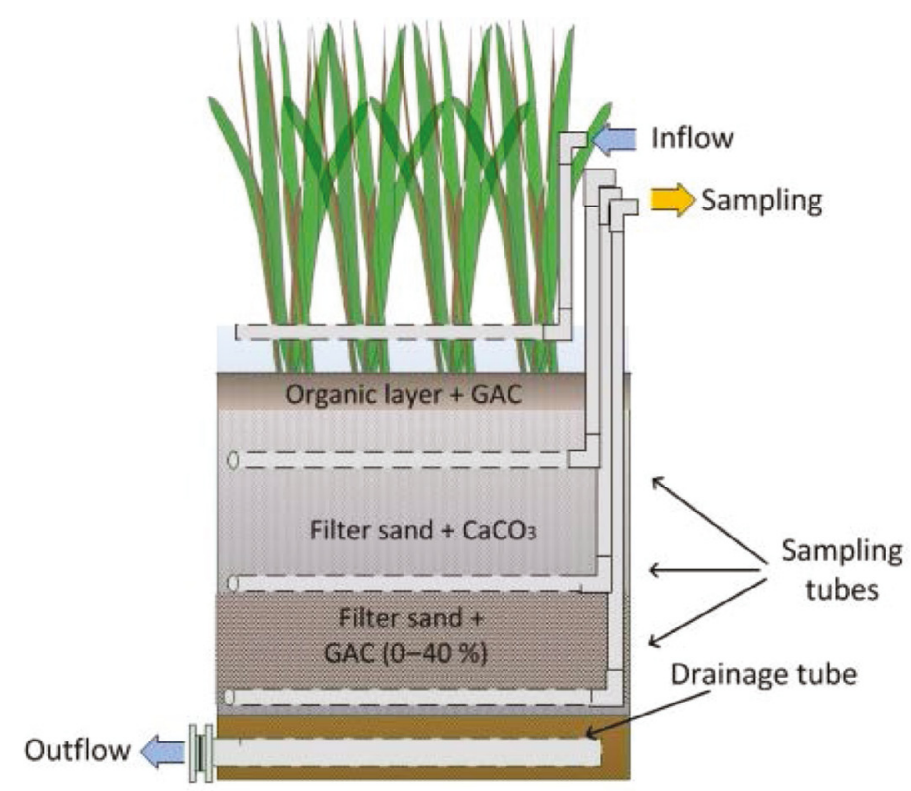

Figure 8: Structure of RSF plus including sampling system. 
installed within the filter area. Each segment has a sampling point close to and far from the inflow (Fig. 7). At these sampling points, sampling tubes are connected to horizontal tubes of different depths (Fig. 8). This enables separate sampling of the different layers.

Samples will be taken regularly during dry weather periods and during CSO events. Besides nutrients and heavy metals, great attention is given to the analysis of micropollutants and faecal bacteria. In addition to that monitoring of the receiving river upstream and downstream of the discharge point will take place.

\section{SUMMARY}

RSFs have been in use in North Rhine-Westphalia for almost 20 years. Water and filter material samples taken from these RSFs show good chemical cleaning capacities, which were also confirmed in further recent studies $[2,3,5]$. Very good retention rates for physico-chemical parameters such as suspended solids, nitrate, phosphorus and heavy metals were detected. Importantly, anthropogenic micropollutants such as pharmaceuticals, pesticides and industrial wastes are also restrained.

Filter material analysis discussed in this article showed that the amount of filter material contamination depends on operational and constructional parameters. Distribution channels clearly prevent inhomogeneous contamination by assuring even loading of the filter material. Organic matter that accumulates during the operational life of the RSF increases sorption processes of pollutants. Even though $\mathrm{CaCO}_{3}$ concentrations decrease depending on the amount and frequency of feeding, remobilization of heavy metals has not been detected so far. Hence, a lifetime of much more than 10 years can be assumed.

Considering the fact that RSFs are only used during overflow events and considering their good cleaning performance, the use of RSFs for purification of WWTP effluent during dry weather periods is worth of consideration. The RSF ${ }^{\text {lus }}$ is a new type of RSF with improved structural and operational parameters. Substrate additives such as GAC are expected to improve cleaning capacities. Segmentation of the filter area and periodic feeding guarantee aerobic filter conditions. Homogeneous loading is achieved by improved distribution channels.

Therefore, the RSF ${ }^{\text {plus }}$ offers a good tool for cost-effective, reliable and low maintenance WWTP effluent polishing in combination with CSO or SSO treatment.

\section{ACKNOWLEDGEMENTS}

The study was funded by the Ministerium für Klimaschutz, Umwelt, Landwirtschaft, Naturund Verbraucherschutz 'Überprüfung und Bewertung von Maßnahmen zur Reduzierung der chemisch-physikalischen und hygienisch-mokrobiologischen Belastung von Fließgewässern am Beispiel der Swist' and by the European Union Horizon 2020, 'Demonstrating synergies in combined natural and engineered processes for water treatment systems (AquaNES)'.

\section{REFERENCES}

[1] European Commission (2000/60/EC), Directive 2000/60/EC of the European Parliament and of the Council establishing a framework for the Community action in the field of water policy, Official Journal L 327, 2000.

[2] Christoffels, E., Mertens, F.M., Kistemann, T. \& Schreiber, C., Retention of pharmaceutical residues and microorganisms at the Altendorf retention soil filter, Water Science \& Technology, 70(9), pp. 1503-1509, 2014. DOI: 10.2166/wst.2014.404.

[3] Scheurer, M., Heß, S., Lüddeke, F., Sacher, F., Güde, H., Löffler, H. \& Gallert, C., Removal of micropollutants, facultative pathogenic and antibiotic resistant bacteria in 
a full-scale retention soil filter receiving combined sewer overflow. Environmental Science, Processes \& Impacts, 17, p. 186, 2015. DOI: 10.1016/j.watres.2010.08.007.

[4] Frechen, F.B., Neue Erkenntnisse zur Mischwasserbehandlung in Retentionsbodenfiltern: Leistungsfähigkeit, Nährstoffe, Hygiene. Planung, Bau und Betrieb: Hennef, Düsseldorf, 2012.

[5] Tondera, K., Koenen, S. \& Pinnekamp, J., Survey monitoring results on the reduction of micropollutants, bacteria, bacteriophages and TSS in retention soil filters. Water Science \& Technology, 68(5), pp. 1004-1012, 2013. DOI: 10.2166/wst.2013.340.

[6] DWA (Deutsche Vereinigung für Wasserwirtschaft, Abwasser und Abfall e.V.), Merkblatt DWA-M 178, Empfehlungen für Planung, Bau und Betrieb von Retentionsbodenfiltern zur weitergehenden Regenwasserbehandlung im Misch- und Trennsystem. ISBN 3-937758-37-2, Hennef, Deutschland, 2005.

[7] MUNLV (Ministerium für Umwelt und Naturschutz, Landwirtschaft und Verbraucherschutz des Landes Nordrhein-Westphalen), Retentionsbodenfilter. Handbuch für Planung, Bau und Betrieb (Retention Soil Filter. Reference Book for Planning, Building and Operation), Düsseldorf, 2003.

[8] MUNLV (Ministerium für Umwelt und Naturschutz, Landwirtschaft und Verbraucherschutz des Landes Nordrhein-Westphalen), Überprüfung und Bewertung von Maßnahmen zur Reduzierung der chemisch-physikalischen und hygienisch-mikrobiologischen Belastung von Fließgewässern am Beispiel der Swist (Examination and Evaluation of Actions for the Reduction of Chemico-Physical and Hygienic-Microbiological Pollution of Watercourses on the Example of the River Swist), Düsseldorf, 2012.

[9] ERC, European Research Council under the European Union's Horizon 2020 research and innovation programme, Demonstrating synergies in combined natural and engineered processes for water treatment systems (AquaNES), 2015. 